\title{
Prompt deliquescence and efflorescence of aerosol nanoparticles
}

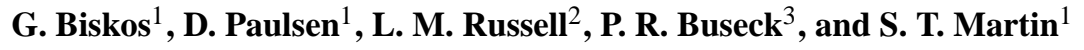 \\ ${ }^{1}$ Division of Engineering and Applied Sciences, Harvard University, Cambridge, MA 02138, USA \\ ${ }^{2}$ Scripps Institution of Oceanography, University of California San Diego, La Jolla, CA 92093, USA \\ ${ }^{3}$ Departments of Geological Sciences and Chemistry/Biochemistry, Arizona State University, Tempe, AZ 85287, USA
}

Received: 11 July 2006 - Published in Atmos. Chem. Phys. Discuss.: 25 July 2006

Revised: 5 October 2006 - Accepted: 10 October 2006 - Published: 17 October 2006

\begin{abstract}
Literature reports have differed on the possibilities of discontinuous and continuous (i.e., prompt and nonprompt) deliquescence and efflorescence of aerosol particles in the nanosize regime. Experiments reported herein using a hygroscopic tandem nano-differential mobility analyzer demonstrate prompt deliquescence and efflorescence of ammonium sulfate particles having diameters from 6 to $60 \mathrm{~nm}$. Apparent nonpromptness can be induced both by operation of the experimental apparatus and by interpretation of the measurements, even though the underlying phase transitions of individual particles remain prompt. No nanosize effect on the relative humidity values of deliquescence or efflorescence is observed for the studied size range. Smaller hygroscopic growth factors are, however, observed for the nanoparticles, in agreement with thermodynamic calculations that include the Kelvin effect. A slightly nonspherical shape for dry ammonium sulfate particles is inferred from their hygroscopically induced reconstruction between 5 and 30\% relative humidity. Our results provide a further understanding of nanoparticle behavior, especially relevant to the growth rates of atmospheric nanoparticles.
\end{abstract}

\section{Introduction}

Despite their small mass, the chemical composition of atmospheric aerosol nanoparticles with diameters as small as $20 \mathrm{~nm}$ can now be approximately determined, in part due to recent advances in analytical instrumentation (McMurry, 2000). Field studies in some locations indicate that ambient particles following nucleation events are composed primarily of ammonium and sulfate ions at variable mixing ratios (Kulmala et al., 2004), although organic compounds have been identified as important constituents of atmospheric nanopar-

Correspondence to: S. T. Martin

(scot_martin@harvard.edu) ticle in some cases (O'Dowd et al., 2002; Allan et al. 2006). Aerosol mass spectra recorded during new-particle nucleation events in Pittsburgh (September 2002) showed that particles having diameters from 18 to $33 \mathrm{~nm}$ were mainly composed of sulfuric acid (Zhang et al., 2004). Hygroscopic growth factors of 25-nm particles following a nucleation event in Gosan, Korea (April 2001), were similar to those of laboratory-generated ammonium sulfate particles (Buzorius et al., 2004). Mass spectra recorded for particles from 6 to $15 \mathrm{~nm}$ during nucleation events in Atlanta (August 2002) showed that ammonium sulfate accounted for the entire sampled nanoparticle mass (Smith et al., 2005). Concurrent measurements of the hygroscopic growth factors were also consistent with ammonium sulfate (Sakurai et al., 2005).

Ammonium sulfate nanoparticles are believed to form in the atmosphere by nucleation in the presence of gas-phase sulfuric acid, water, and ammonia (Ball et al., 1999). Although the exact mechanism of new-particle formation is not yet fully understood, theoretical predictions indicate that ternary nucleation could explain the high particle-formation rates observed in the atmosphere (Napari et al., 2002). Once formed, the freshly nucleated particles grow, through processes of condensation and coagulation, to diameters large enough to become optically active. During the growth process, a principal factor affecting the condensation and coagulation rates is particle hygroscopicity because physical state (i.e., solid or liquid) and particle diameter vary with relative humidity (RH). Once large enough to be optically active, the particles influence the radiative properties of the atmosphere and thus directly the climate of the Earth at regional and global scales. The larger particles also indirectly affect the Earth's climate through their action on cloud formation.

The hygroscopic behavior of nanoparticles can be different from that of their large-particle counterparts because the relative contribution of the surface term to the free energy of a particle increases markedly for sub- $100 \mathrm{~nm}$ particles (Chen, 1994; Mirabel et al., 2000; Djikaev et al., 2001; Russell and

Published by Copernicus GmbH on behalf of the European Geosciences Union. 
Ming, 2002; Biskos et al., 2006a). Sodium chloride nanoparticles have been investigated most thoroughly. One effect is that the deliquescence and efflorescence relative humidity values (hereafter, DRH and ERH, respectively) of sodium chloride particles increase for mobility diameters smaller than 40 nm (Hämeri et al., 2001; Biskos et al., 2006a). A second effect is that the hygroscopic growth factor of the sodium chloride nanoparticles decreases because of the Kelvin effect (Hämeri et al., 2001), although quantitative agreement between predictions and observations must also take into account a size-dependent shape factor in the Knudsen regime (Biskos et al., 2006b).

Measurements of the hygroscopic properties of ammonium sulfate nanoparticles have also been made, and intermediate growth factors were observed for $\mathrm{RH}$ values around the DRH (Hämeri et al., 2000). The results led Mirabel et al. (2000) in a theory paper to introduce the concepts of prompt and nonprompt deliquescence. In an operational definition, prompt and nonprompt deliquescence respectively correspond to discontinuous and continuous increases of particle diameter during the phase transition that accompanies increasing RH. Mirabel et al. (2000) hypothesized that nanosized particles have nonprompt behavior in contrast to the prompt behavior of their large-particle counterparts (e.g., as observed in the large-particle experiments of Cohen et al., 1987; Tang and Munkelwitz, 1994; Weis and Ewing, 1996; Cziczo et al., 1997; Onasch et al., 1999; Wise et al., 2005). Djikaev et al. (2001) subsequently modeled the deliquescence process for nanosized particles and reported an absence of nonprompt behavior. In further modeling papers, Russell and Ming (2002) and Topping et al. (2005) also predicted that prompt deliquescence of nanoparticles should occur. In this paper, we provide new experimental measurements of the hygroscopic properties of ammonium sulfate nanoparticles using a tandem nano-differential mobility analyzer (Rader and McMurry, 1986; Chen et al., 1998). Our results show that both deliquescence and efflorescence of ammonium sulfate nanoparticles are prompt and that the earlier data of Hämeri et al. (2000), which has been interpreted to support nonprompt deliquescence, can instead be reproduced by an artifact tied to the operation of the experimental apparatus.

\section{Experimental}

A hygroscopic tandem nano-differential mobility analyzer (TnDMA) was employed to study the deliquescence, the efflorescence, and the hygroscopic growth of monodisperse ammonium sulfate particles having mobility diameters from 6 to $60 \mathrm{~nm}$. Experiments were carried out for particles generated both by electrospray and by atomization to test for any influence of preparation method on the results (e.g., possible chemical impurities enriched in nanoparticles).
The electrospray aerosol generator (TSI Model 3480) employed 10- and 100-mM aqueous solutions of ammonium sulfate (EMD Chemical Inc., 99.5\% purity) for nanoparticles of 6-20 nm and 40-60 nm mobility diameter, respectively. High-purity water (Barnstead Model D8971; $18 \mathrm{M} \Omega \mathrm{cm}$ ) for the solutions was prepared by consecutive steps including filtration, ultraviolet irradiation, and reverse osmosis. The primary aerosol particles exiting the $40-\mu \mathrm{m}$ capillary tube of the electrospray generator were diluted with $2 \mathrm{Lpm}$ filtered dry air, resulting in an aerosol stream of below $0.1 \% \mathrm{RH}$. The aerosols had lognormal particle number size distributions. From the $10-\mathrm{mM}$ solution, the mode diameter was $10 \mathrm{~nm}$, the geometric standard deviation was 1.3 , and the integrated particle number concentration was $10^{6} \mathrm{~cm}^{-3}$. The respective quantities for the 100-mM solution were $15 \mathrm{~nm}, 1.6$, and $6 \times 10^{6} \mathrm{~cm}^{-3}$.

An atomizer (TSI Model 3076) was also used to generate aerosol samples. A $0.1 \mathrm{wt} \%$ solution was atomized in $\mathrm{N}_{2}$, following a method similar to that of Hämeri et al. (2000). The polydisperse aerosol was dried to below $10 \% \mathrm{RH}$ by mixing with dry air and passing through a diffusion dryer (TSI Model 3062). The mode diameter of the lognormal particle number size distribution was $15 \mathrm{~nm}$, the geometric standard deviation was 1.4 , and the integrated particle number concentration was $4 \times 10^{6} \mathrm{~cm}^{-3}$.

Figure 1 shows a schematic layout of the TnDMA used in the experiments. A description of an earlier version of the apparatus was provided in Biskos et al. (2006a). In brief, the polydisperse aerosol particles were passed through a ${ }^{85} \mathrm{Kr}$ neutralizer (TSI Model 3077) and a first nano-DMA (TSI Model 3085). The resulting monodisperse particles were then exposed to an RH history through a series of one or two single-tube Nafion humidity exchangers (Perma Pure Model MD-110), after which their number size distribution was measured with a second nano-DMA and an ultrafine CPC (TSI Model 3025). The RH history allowed either deliquescence- or efflorescence-mode experiments to be carried out. For instance, in deliquescence mode, the RH history of the aerosol prior to a number-size-distribution measurement was $5 \% \rightarrow X \%$, where $X$ was increased stepwise as the independent variable of an experiment (i.e., $X=\mathrm{RH}_{\mathrm{a}}$ of Fig. 1). In efflorescence mode, the RH history prior to a number-size-distribution measurement was $5 \% \rightarrow 95 \% \rightarrow X \%$.

Modifications to the system described by Biskos et al. (2006a) were as follows. DMA-2 employed closedloop recirculation for the sheath flow instead of the openflow circulation. This change somewhat improved the precision of replicate experiments by ensuring that the sheath flow-in was exactly balanced by the sheath flow-out. The recirculation setup depicted in Fig. 1 employed a blower (Minispiral Model SE12RE21SA) that collected the excess flow from the DMA and drove it through (1) a hydrophobic filter (Whatman Model 6702-7500) to remove particles, (2) a heat exchanger (Lytron Model C-HX-4105G1SB) to 


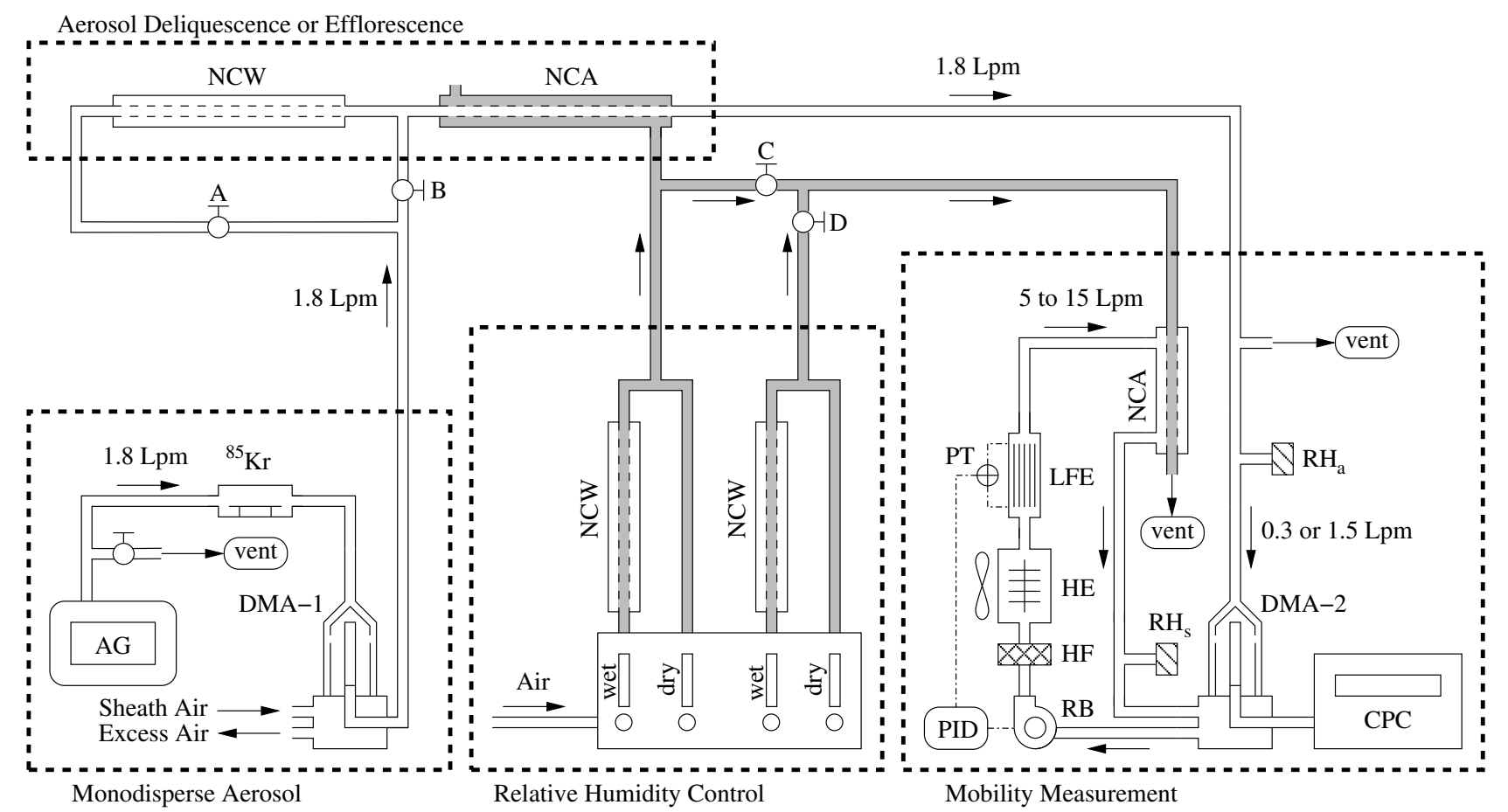

Fig. 1. Schematic layout of the tandem nano-DMA. Key: AG, aerosol generator (electrospray or atomizer); ${ }^{85} \mathrm{Kr}$, Krypton source aerosol neutralizer; DMA, differential mobility analyzer; CPC, condensation particle counter; LFE, laminar flow element; HE, heat exchanger; HF, high efficiency particulate air (HEPA) filter; PID, proportional-integral-derivative controller; PT, pressure transducer; RB, recirculation blower; NCA, Nafion conditioner with air; NCW, Nafion conditioner with water; $\mathrm{RH}_{\mathrm{S}}$, sheath-flow relative-humidity monitor of DMA-2; and $\mathrm{RH}_{\mathrm{a}}$, aerosol-flow relative-humidity monitor of DMA-2. Vent is connected to the house hood. Filtered dry house air is used for the sheath flow of DMA-1 and for the relative humidity control. In a deliquescence-mode experiment, valve A is closed and valve B is open. In an efflorescence-mode experiment, valve $\mathrm{A}$ is open and valve $\mathrm{B}$ is closed. Valve $\mathrm{C}$ is open and valve $\mathrm{D}$ is closed to set $\mathrm{RH}_{\mathrm{s}}=\mathrm{RH}_{\mathrm{a}}$. For independent values of $\mathrm{RH}_{\mathrm{s}}$ and $\mathrm{RH}_{\mathrm{a}}$ (e.g., $\mathrm{RH}_{\mathrm{s}}=\mathrm{RH}_{\mathrm{a}}+3 \%$ ), valve $\mathrm{C}$ is closed and valve $\mathrm{D}$ is open. Gray and clear paths denote $\mathrm{RH}$-controlling and RH-controlled flows, respectively. See Biskos et al. (2006a) for further description of the elements in this figure.

equilibrate the temperature (heated by $2-3 \mathrm{~K}$ in the compressive blower), (3) a laminar flow element (Furness Controls Model FCO96-20) coupled to a pressure transducer (Aschroft Model CXLdp) and a proportional-integral-derivative (PID) controller (Omega Model CNI16D52-C24-DC) to provide feedback to the blower speed and thereby control the flow rate, and (4) a multiple-tube Nafion conditioner (Permapure Model PD-50T) to rapidly adjust the relative humidity to the desired value. The flow then reentered the DMA as the sheath flow, which was regularly calibrated by use of a Gilibrator bubble flow meter. In the usual mode of operation, we set the relative humidity of the sheath flow $\left(\mathrm{RH}_{\mathrm{s}}\right)$ equal to the relative humidity of the aerosol (i.e., $\mathrm{RH}_{\mathrm{s}}=\mathrm{RH}_{\mathrm{a}}$ ) by opening valve $\mathrm{C}$ and closing valve $\mathrm{D}$. For specific experiments designed to compare our results with those of Hämeri et al. (2000), we closed valve $\mathrm{C}$ and opened valve $\mathrm{D}$ and then set $\mathrm{RH}_{\mathrm{s}}=\mathrm{RH}_{\mathrm{a}}+3 \%$ by using an independent $\mathrm{RH}$ generator (cf. Fig. 1). We employed $1.5 \mathrm{Lpm}$ for the aerosol flow and $15 \mathrm{Lpm}$ for the sheath flow at 6-nm mobility diameter and steadily decreased the respective flows for increasing mobility diameter, i.e., $0.3 \mathrm{Lpm}$ and $5 \mathrm{Lpm}$ at $60-\mathrm{nm}$ mobility diameter.
Accuracy and precision of the particle-sizing and relative humidity measurements were as follows. Regarding the accuracy of particle sizing (Kinney et al., 1991), the sheath and aerosol flows were calibrated to within $1 \%$ using a Gilibrator bubble flow meter, and the voltage of the central rod was measured to within $0.1 \%$ (up to $500 \mathrm{~V}$ ). These uncertainties, combined with the uncertainties in the geometric dimensions of the DMA, propagated as an uncertainty of $2.5 \%$ in the classified particle diameter and, therefore, in the measured growth factor. (An alternative procedure using monodisperse polystyrene latex (PSL) spheres led to an uncertainty of 3\%.) The precision of the TnDMA measurements of the particle sizes was within $2 \%$ based upon replicate measurements and did not change throughout the course of the experiments. As an experimental check of these accuracies and precisions, the sizing agreement of the two DMAs was within $2.5 \%$ from 10 to $100 \mathrm{~nm}$ using $\mathrm{NaCl}$ particles generated by a vaporizationcondensation method and analyzed below 5\% RH (cf. Biskos et al. 2006a). The two RH sensors (Omega Model HX93AV) were regularly calibrated against a chilled mirror hygrometer (Kahn Instruments Inc. Model S4000) from 5 to 95\% RH. 
(a) Electrospray Deliquescence

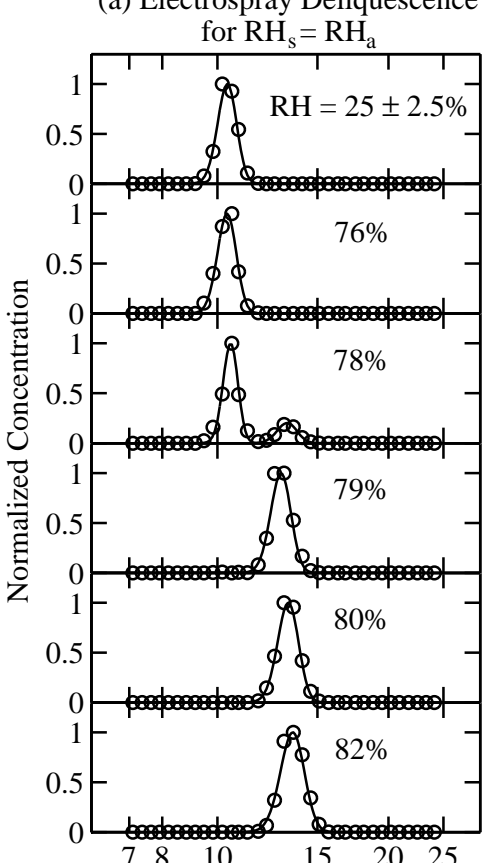

(b) Atomization Deliquescence

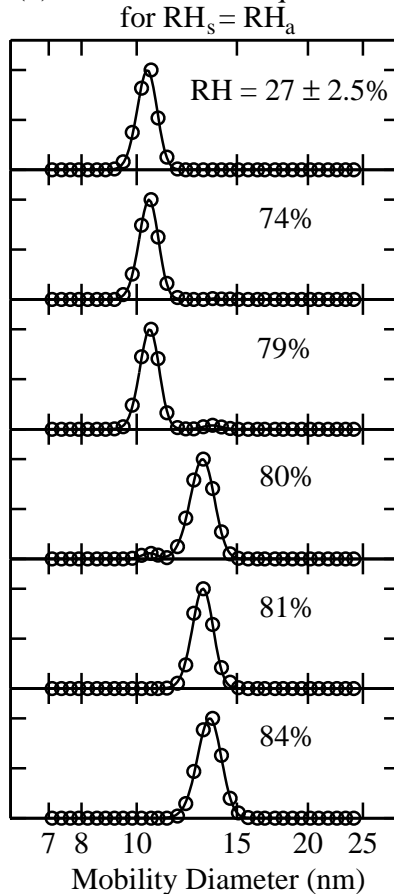

(c) Electrospray Deliquescence for $\mathrm{RH}_{\mathrm{s}}=\mathrm{RH}_{\mathrm{a}}+3 \%$

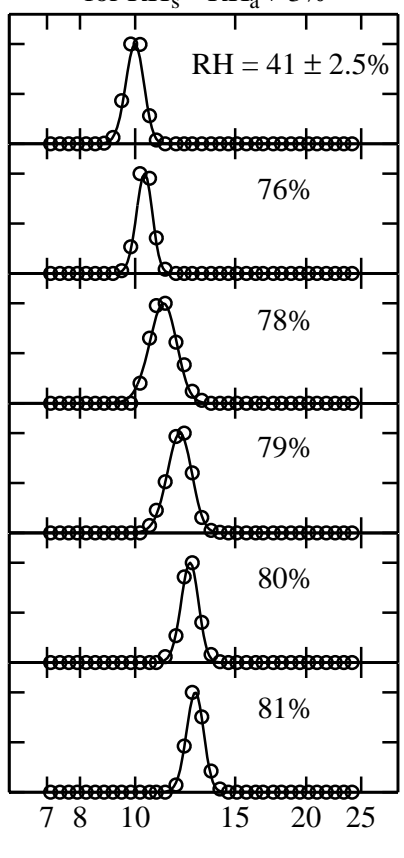

Fig. 2. Deliquescence-mode measurements of ammonium sulfate aerosol particles generated by electrospray or atomization. The RH history in each measurement is $5 \% \rightarrow X \%$, where $X$ is the value given in each panel. Measured (circles) and fitted (solid lines; one-peak Gaussian function) normalized number size distributions are shown for increasing RH. In (a) and (b), the RH of the sheath flow equals that of the aerosol flow. In (c), the RH of the sheath flow is $+3 \%$ compared to that of the aerosol flow (Hämeri et al., 2000). Temperature is $298 \mathrm{~K}$. The dry mobility diameter is $10 \mathrm{~nm}$.

\section{Results and discussion}

The results of a deliquescence-mode experiment are shown in Fig. 2 for particles having a 10-nm dry mobility diameter. The normalized number size distributions show that deliquescence occurs at $79 \pm 2.5 \% \mathrm{RH}$, which is consistent with the large-particle value of $79.5 \%$ (cf. Martin, 2000). Apparent differences in the deliquescence relative humidity (e.g., $79 \%$ in Fig. 2a and $80 \%$ in Fig. 2b) lie within the day-to-day variability of the precision of the RH measurements. The hygroscopic responses for particles generated by electrospray and atomization are similar.

Provided that $\mathrm{RH}_{\mathrm{s}}=\mathrm{RH}_{\mathrm{a}}$, there is a prompt phase change for a $1 \%$ increase in RH from a mode centered at $10 \mathrm{~nm}$ to one centered at $13 \mathrm{~nm}$ following deliquescence (Figs. 2a and b). In some measurements, two separate peaks, which correspond to externally mixed populations of aqueous and solid particles, are observed for $\mathrm{RH}_{\mathrm{a}}$ close to DRH. This effect arises from slight heterogeneities of relative humidity in the apparatus. Once the particles are aqueous above $80 \% \mathrm{RH}$, further increase of the RH results in water condensation and, therefore, additional diameter growth.

For $\mathrm{RH}_{\mathrm{s}}=\mathrm{RH}_{\mathrm{a}}+3 \%$, which follows the protocol of Hämeri et al. (2000), there is an apparent nonprompt phase change: the apparent mode diameter increases continuously from
$10.3 \mathrm{~nm}$ at $76 \% \mathrm{RH}$, to $10.7 \mathrm{~nm}$ at $78 \% \mathrm{RH}$, to $11.2 \mathrm{~nm}$ at $79 \% \mathrm{RH}$, to $12.5 \mathrm{~nm}$ at $81 \% \mathrm{RH}$ (Fig. 2c). Contrary to the experiments in which $\mathrm{RH}_{\mathrm{s}}=\mathrm{RH}_{\mathrm{a}}$, no distinct peaks that correspond to the two phases of the particles (i.e., solid and aqueous) are observed. The size distribution, however, widens for 78 and $79 \% \mathrm{RH}$. Similar behavior is also observed by us for $10-\mathrm{nm} \mathrm{NaCl}$ particles (see Fig. S1). The apparent nonpromptness, however, does not reflect the true particle behavior but rather is an artifact of the experimental method and analysis, as next explained.

The apparent nonprompt deliquescence occurs for $\mathrm{RH}_{\mathrm{s}}=\mathrm{RH}_{\mathrm{a}}+3 \%$ because the particles deliquesce within DMA-2. There is a slow equilibration of the RH between the laminar aerosol and sheath flows, arising from diffusive mixing, as well as limited convective mixing, during transport through the DMA classification column. For instance, consider $\mathrm{RH}_{\mathrm{s}}=80 \%$ and $\mathrm{RH}_{\mathrm{a}}=77 \%$ when the flows enter the DMA. The particles in the aerosol flow are not immediately exposed to $80 \% \mathrm{RH}$ when the aerosol and sheath flows merge at the top of the classification column. Rather, after traveling some distance in the classification column as solid particles of smaller mobility diameter, they abruptly deliquesce to form aqueous particles of increased mobility diameter. The classified particles emerging from the DMA therefore have an apparent mobility diameter that is a weighted-average of 
their transport time as solid and aqueous particles. Mikhailov et al. (2004; Fig. 14 therein) reported a similar effect in their study of 100-nm sodium chloride particles. Numerical modeling by us of air flow and diffusive-convective RH mixing is consistent with deliquescence during particle transport inside the DMA (see Fig. S2).

This RH mixing effect inside the DMA leads to the observation of a smoothly increasing growth factor. As the RH values of the sample and sheath flows increase during a scan (e.g., $\mathrm{RH}_{\mathrm{s}}=81 \%$ and $\mathrm{RH}_{\mathrm{a}}=78 \%$ ), deliquescence occurs further upstream in the classification column, and the weightedaveraged apparent mobility diameter increases. According to this explanation, the underlying deliquescence events are prompt, and the apparent nonpromptness results, as an artifact, because these abrupt deliquescence events occur inside the classification column. This explanation makes unnecessary our earlier hypothesis (Biskos et al., 2006a, b) of impurities concentrated by atomization as the explanation for literature reports of nonprompt deliquescence of nanoparticles. Furthermore, the apparent widening of the distribution from 77 to $79 \%$ RH (Fig. 2c) can be explained by small RH variations in the flow field, causing some particles to deliquesce earlier and some later along their paths within the DMA.

Efflorescence-mode experiments for particles having a 10nm dry mobility diameter show an apparent nonprompt behavior even for $\mathrm{RH}_{\mathrm{s}}=\mathrm{RH}_{\mathrm{a}}$ (Fig. 3). Here, the explanation for apparent nonpromptness differs from that provided above for the deliquescence-mode experiments. In efflorescence mode, the mean mobility diameter of the aqueous particles decreases for decreasing $\mathrm{RH}$, which is explained by the evaporation of water that accompanies reversible hygroscopic growth. For $\mathrm{RH}>35 \%$, the observations show that the decrease of mobility diameter with RH (i.e., $d_{m}^{\prime}=\mathrm{d} d_{m} / \mathrm{dRH}$ ) proceeds rather gently and in agreement with quantitative predictions (see Appendix concerning the hygroscopic growth factor). For 34 to $31 \% \mathrm{RH}$, however, $d_{m}^{\prime}$ increases greatly and diverges from predictions. At $30 \% \mathrm{RH}$, $d_{m}^{\prime}$ abruptly goes to zero, indicating that crystallization is complete. Unless a tandem-DMA data analysis algorithm is used (e.g., Stolzenburg et al., 2005; Cubison et al., 2005), these measurements could erroneously be interpreted to suggest that particle crystallization for $\mathrm{RH}_{s}=\mathrm{RH}_{\mathrm{a}}$ is nonprompt because no abrupt shift of narrow, distinct peaks is observed during the RH scan from 35 to $30 \%$. The increase both of the width of the size distribution from 34 to $31 \%$ RH and of $d_{m}^{\prime}$ over this same range, however, indicates that a different explanation is correct: there are two overlapping, incompletely resolved modes corresponding to solid and aqueous particles.

This explanation can be developed further, as follows. For 10-nm dry mobility-diameter particles of ammonium sulfate, the hygroscopic growth factor at $34 \% \mathrm{RH}$ is 1.075 (see Appendix and also Fig. 4). For the typical operating conditions of DMA-1 (i.e., an aerosol-to-sheath flow ratio of 1:10), the size distribution of the monodisperse aerosol has a onesigma geometric standard deviation (gsd) of 1.04. The data

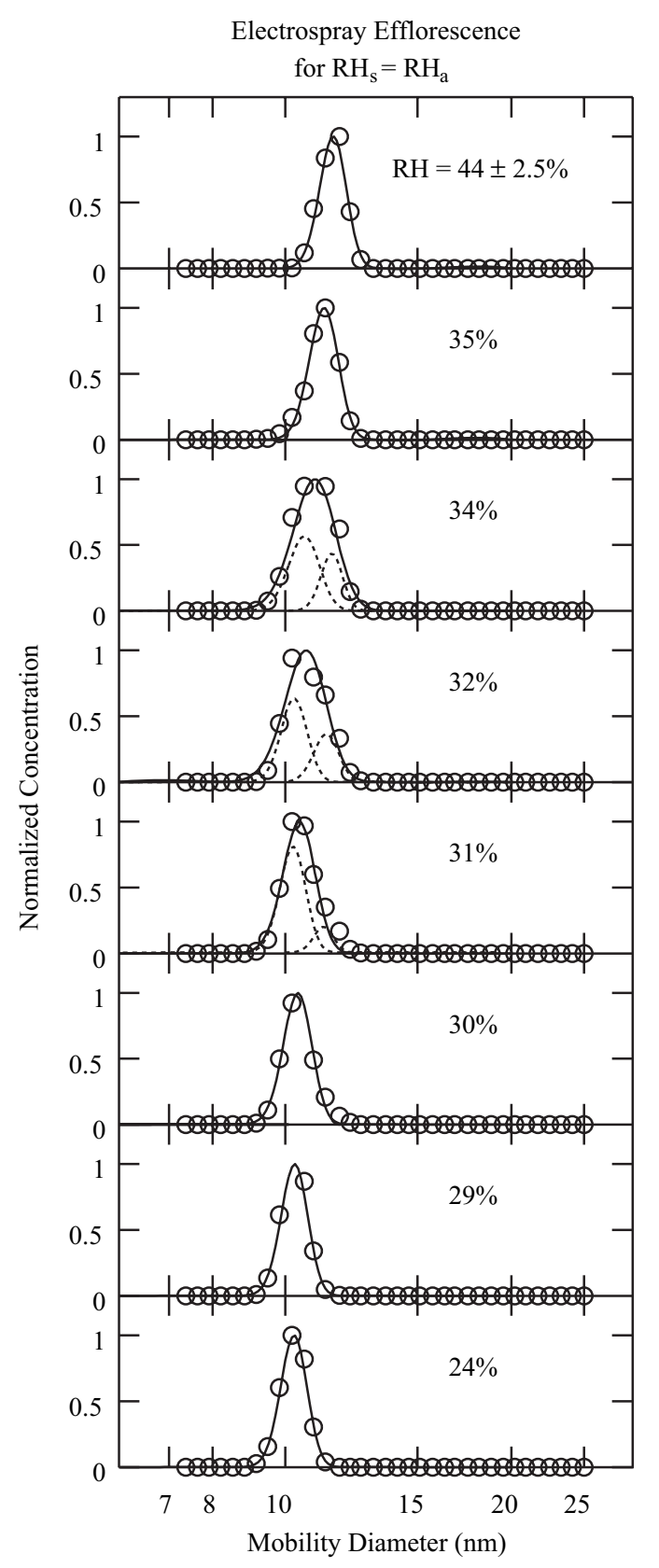

Fig. 3. Efflorescence-mode measurements of ammonium sulfate aerosol particles generated by electrospray. The RH history in each measurement is $5 \% \rightarrow 95 \% \rightarrow X \%$, where $X$ is the $\mathrm{RH}$ value given in each panel. Measured (circles) and fitted (solid lines) normalized number size distributions are shown for decreasing RH. At 32 and $34 \% \mathrm{RH}$, the apparent widening of the normalized number size distributions arises from overlapping peaks of dry and aqueous aerosol particles, which are resolved by the two-peak Gaussian fit shown in the figure (dashed lines). Temperature is $298 \mathrm{~K}$. The dry mobility diameter is $10 \mathrm{~nm}$. 

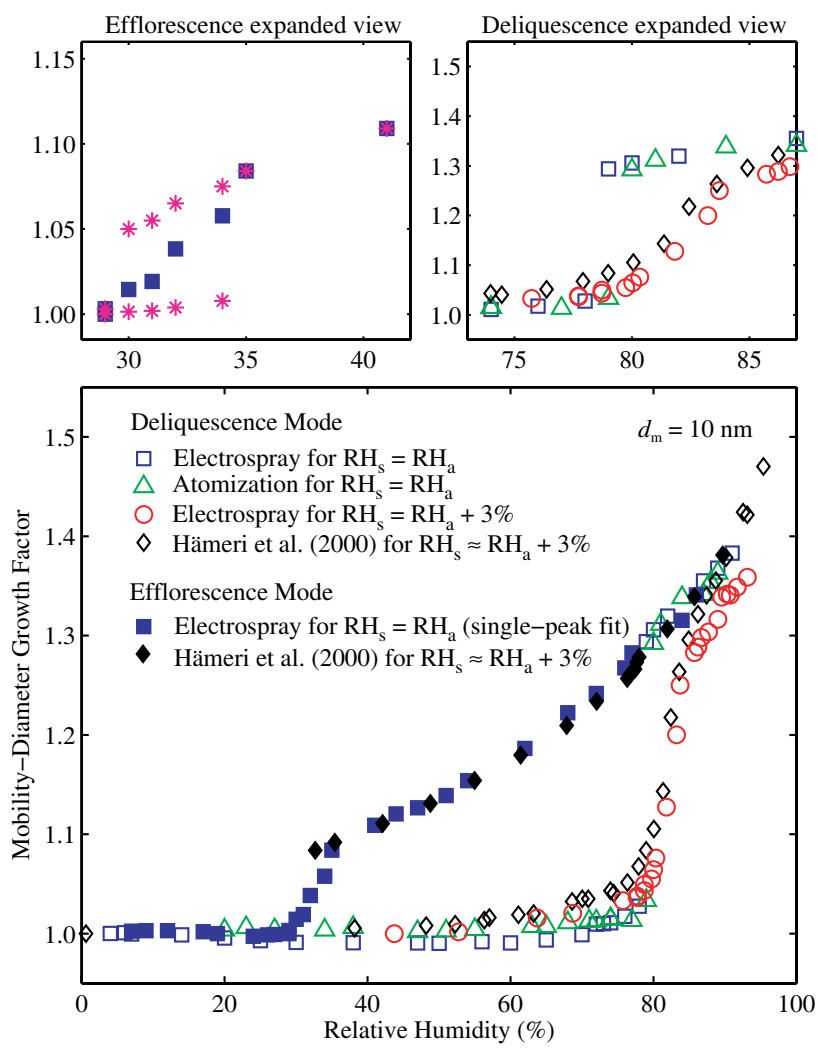

Fig. 4. Hygroscopic growth curves showing that prompt deliquescence and efflorescence occur provided that $\mathrm{RH}_{\mathrm{S}}=\mathrm{RH}_{\mathrm{a}}$ (cf. caption to Fig. 2). Temperature is $298 \mathrm{~K}$. The dry mobility diameter is $10 \mathrm{~nm}$. The ordinate values are calculated from the measurements (e.g., Figs. 2 and 3) using Eq. (A1). Solid symbols were recorded during efflorescence-mode experiments, and open symbols were recorded during deliquescence-mode measurements. Diamonds show the data of Hämeri et al. (2000), for which $\mathrm{RH}_{\mathrm{s}} \approx \mathrm{RH}_{\mathrm{a}}+3 \%$. The upper panels show expanded views of the efflorescence-mode data from 30 to $40 \% \mathrm{RH}$ (left panel) and the deliquescence-mode data from 75 to $85 \% \mathrm{RH}$ (right panel). The solid blue points in the main and upper panels show the efflorescence data analyzed using a one-peak fit whereas the magenta points in the upper panel show the data analyzed using a two-peak fit of overlapping dry and aqueous modes (cf. Fig. 3).

for $34 \%$ RH in Fig. 3 are successfully fit by two Gaussian peaks having gsd's of 1.04 and a geometric mode separation of 1.07. The existence of two modes in the efflorescence data across $3 \% \mathrm{RH}$ (i.e., 34 to $31 \% \mathrm{RH}$ ), compared to across just $1 \% \mathrm{RH}$ for the deliquescence data, arises from either greater $\mathrm{RH}$ gradients for lower RH values in the NCA (Fig. 1) or stochastic nucleation and crystallization of individual aerosol particles during the residence time in the apparatus (Martin, 2000).

The hygroscopic behavior of 10-nm dry mobility-diameter particles is summarized in Fig. 4, including a comparison to the results of Hämeri et al. (2000). The points in Fig. 4 correspond to the mode diameters of the fits to the deliquescence
Table 1. Density $\rho\left(\mathrm{kg} \mathrm{m}^{-3}\right)$, water activity $a_{w}$, and surface tension $\sigma_{a q}\left(\mathrm{~N} \mathrm{~m}^{-1}\right)$ of ammonium sulfate for $0<w_{t}<78 \%$. Data sources: $\rho_{s}$ (Perry and Green, 1997), $\rho_{a q}$ and $a_{w}$ (Tang et al., 1997), and $\sigma_{a q}$ (Pruppacher and Klett, 1997).

$$
\begin{array}{ll}
\rho_{s}=1770 & \\
\rho_{\mathrm{aq}}=997.1+\sum A_{i} w_{t}^{i} & A_{1}=5.920 \\
& A_{2}=-5.036 \times 10^{-3} \\
& A_{3}=1.024 \times 10^{-5} \\
a_{w}=1.0+\sum C_{i} w_{t}^{i} & C_{1}=-2.715 \times 10^{-3} \\
& C_{2}=3.113 \times 10^{-5} \\
& C_{3}=-2.336 \times 10^{-6} \\
& C_{4}=1.412 \times 10^{-8} \\
\sigma_{a q}=0.072+\frac{0.0234 w_{t}}{100-w_{t}} & \\
\hline
\end{array}
$$

and efflorescence data. For $\mathrm{RH}_{\mathrm{s}}=\mathrm{RH}_{\mathrm{a}}$, prompt deliquescence occurs for both the electrosprayed and the atomized particles (upper right panel). For $\mathrm{RH}_{\mathrm{s}}=\mathrm{RH}_{\mathrm{a}}+3 \%$, however, intermediate growth factors are recorded because deliquescence occurs within the classification column. The results of Hämeri et al. (2000), also recorded using $\mathrm{RH}_{\mathrm{s}}=\mathrm{RH}_{\mathrm{a}}+3 \%$, are in qualitative agreement with this nonprompt trend. The efflorescence points in the bottom panel of Fig. 4 are shown for a onepeak fit to the data (i.e., apparent nonprompt efflorescence); the efflorescence points in the upper left panel correspond to solid- and aqueous-modes of a two-peak fit to the data for $31 \%<\mathrm{RH}<34 \%$ (cf. discussion of Fig. 3).

The slope of the intermediate growth factors depends on several instrumental factors. For instance, an increasing difference between $\mathrm{RH}_{\mathrm{a}}$ and $\mathrm{RH}_{\mathrm{s}}$ decreases the slope further. Likewise, the RH mixing rate within DMA-2 is affected both by the design of the DMA and the flow rates through it. Sizing of larger particles typically implies lower flow rates and therefore longer residence times of the particles in the classifier, allowing deliquescence closer to the DMA entrance. Two designs of Hauke-type DMA's (namely, one for particles smaller than $30 \mathrm{~nm}$ and another for those larger than $30 \mathrm{~nm}$ ) are employed by Hämeri et al. (2000) (cf. Table 1 therein). In comparison, a TSI nano-DMA is used in our apparatus. These factors provide a possible explanation for the difference in the extent of nonpromptness between the results reported in this study (red circles in Fig. 4) and those in Hämeri et al. (2000) (black open diamonds). Differences in the design and the operating conditions of the DMA's may explain another observation in Hämeri et al. (2000) that 15and $30-\mathrm{nm}$ particles appear to have a more prompt deliquescence than 8- and 10-nm particles (cf. Fig. 2 therein).

The hygroscopic behavior for 6- to 60-nm dry mobilitydiameter particles generated by electrospray is summarized in Fig. 5, including a comparison to model predictions of hygroscopicity. For fixed relative humidity, the hygroscopic growth of nanoparticles decreases with decreasing particle 


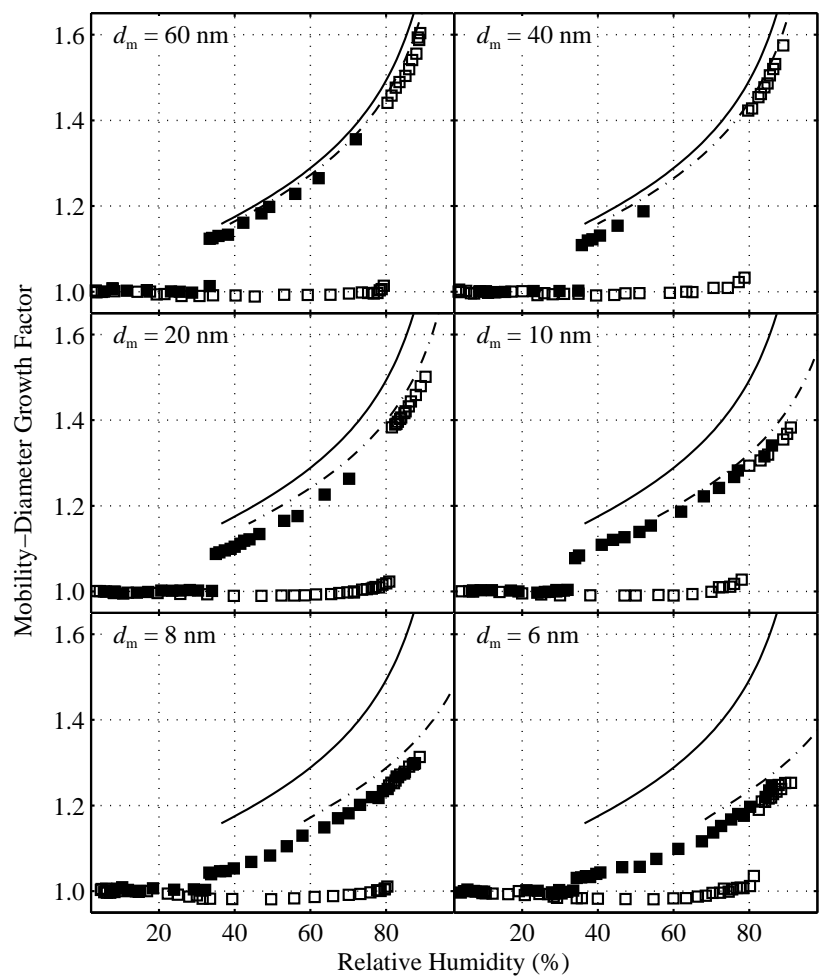

Fig. 5. Hygroscopic growth curves of ammonium sulphate aerosol particles generated by electrospray. Open symbols were recorded during deliquescence-mode measurements. Solid symbols were recorded during efflorescence-mode experiments and were analyzed by using either one- or two-peak fits, as necessary (cf. Figs. 3 and 4). Lines show the growth factors of models that omit (solid line) and include (dot-dashed line) the Kelvin effect (viz. models 1 and 2 described in the Appendix). Models are evaluated for $0<w_{t}<78 \%$.

size. For example, the mobility-diameter growth factor at $80 \% \mathrm{RH}$ is 1.22 for 6 -nm particles compared to 1.44 for 60 $\mathrm{nm}$ particles. For comparison, for sodium chloride particles the analogous values are 1.51 and 1.77, respectively (Biskos et al., 2006b). The model predictions in Fig. 5 differ on whether the Kelvin effect is included or not (see Appendix). The measurements agree within $4 \%$ with the model predictions that include the Kelvin effect. This agreement suggests that the physical parameters used in the calculations (i.e., the surface tension, the density of the aqueous particles, the density of the dry particles, and the relationship of activity to weight percent composition) are known accurately enough to predict the hygroscopic growth of ammonium sulfate nanoparticles. Even so, there appears to be a systematic bias of 1 to $4 \%$ in the comparisons between the model predictions of the growth factor and the measurements, with slightly greater bias for decreasing particle size.

The small systematic bias between the model predictions and the measurements can be explained by a shape factor correction of 1.02, thus implying slightly nonspherical particles. This explanation is corroborated by the decrease of the

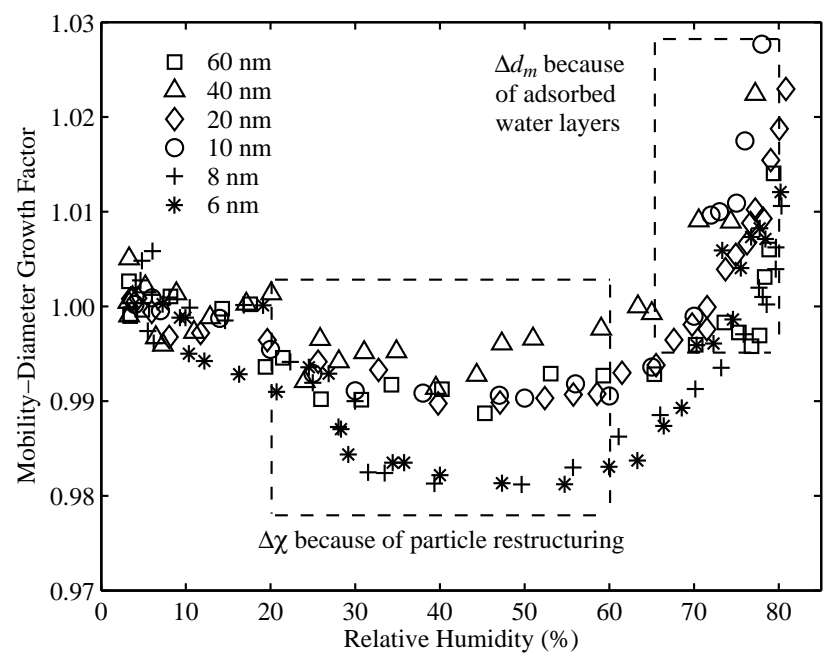

Fig. 6. Comparison at intermediate RH values (i.e., below DRH) of the hygroscopic growth factors $g$ of ammonium sulfate aerosol particles of 6- to 60-nm mobility diameter during deliquescence-mode experiments. Particles are generated by electrospray. Equation (A1) provides the definition of $g(\mathrm{RH})$. Between 20 and 60\% RH, $g(\mathrm{RH})$ decreases because the particle shape factor $\chi(\mathrm{RH})$ decreases (i.e., approaching spherical shape). Between 65 and $80 \% \mathrm{RH}, g(\mathrm{RH})$ increases because adsorbed water layers increase the mobility diameter $d_{m}(\mathrm{RH})$. The RH history of the particles is $5 \% \rightarrow X \%$, where $X$ is the abscissa value. The observations do not change for an $\mathrm{RH}$ history that includes a pre-treatment step of $5 \% \rightarrow 90 \% \rightarrow 5 \% \rightarrow X \%$ (data not shown), in contrast to the behavior of sodium chloride particles (Biskos et al., 2006b). For all the measurements, $\mathrm{RH}_{\mathrm{a}}=\mathrm{RH}_{\mathrm{s}}$.

growth factor during deliquescence-mode experiments from 1.00 for $\mathrm{RH}<5 \%$ to 0.99 to 0.98 for $20 \%<\mathrm{RH}<60 \%$ (Fig. 6). This decrease in mobility diameter, most evident for particles smaller than $10 \mathrm{~nm}$, arises from changes in particle shape and is driven by restructuring to more stable forms. The implication is that the mobility diameter for $\mathrm{RH}<5 \%$ is 1 to $4 \%$ larger than the volume-equivalent diameter, so that the observed growth factors are systematically 1 to $2 \%$ smaller than the predicted growth factors. (The increase in growth factor between 65 and $80 \% \mathrm{RH}$ arises from adsorbed layers of water; Romakkaniemi et al., 2001.)

The data in Fig. 5 show that there is no nanosize effect on the deliquescence relative humidity $(79.5 \%)$ or the efflorescence relative humidity $(35 \%)$ of ammonium sulfate. This conclusion is subject to the caveats of the size range investigated (6 to $60 \mathrm{~nm})$, the experimental uncertainty $(2.5 \%$ in $\mathrm{RH}$ ), the time allowed for a phase transition (between 1 and $2 \mathrm{~s}$ ), and the particle preparation methods employed. The data of Hämeri et al. (2000) also suggest an absence of a nanosize effect provided that the DRH value is taken at the median growth factor of the nonprompt observations. The experimental observations of an absence of a nanosize effect for DRH disagree with theoretical predictions, which have hypothesized based upon assumed physical parameters that 
the DRH should increase for decreasing particle size (Chen, 1994; Russell and Ming, 2002; Topping et al., 2005). The observed ERH of ammonium sulfate particles reported in this paper are in agreement, within experimental uncertainty, with those predicted by Gao et al. (2006).

The absence in the experimental observations of a nanosize effect for the deliquescence and efflorescence phase transitions of ammonium sulfate differs from the presence of an effect for sodium chloride, for which deliquescence shifts from $75 \%$ for large particles to $87 \% \mathrm{RH}$ for a 6 -nm particle and efflorescence from $45 \%$ to $53 \%$ for a similar change in particle size (Biskos et al., 2006b). A possible implication is that the surface properties of ammonium sulfate differ from those of sodium chloride.

In conclusion, the measurements presented in this paper show that deliquescence and efflorescence of ammonium sulfate nanoparticles are prompt, similar to their large-particle counterparts. Literature reports of nonprompt deliquescence are explained by the operating conditions of the DMA and the interpretation of the data. There is no discernable nanosize effect on the deliquescence and efflorescence relative humidity values of ammonium sulfate particles, in contrast to the phase transitions of sodium chloride nanoparticles. The hygroscopic growth factors observed for ammonium sulfate nanoparticles agree with thermodynamic predictions that take into account the Kelvin effect. An accurate description of the hygroscopic behavior of nanoparticles, including their phase transitions and growth factors, is a foundational component of accurate models of nucleation and growth processes of atmospheric nanoparticles.

\section{Supporting information available}

The data shown in Figs. 2 to 6 , as well as the supplementary Figs. S1 and S2, are available electronically (http://www.atmos-chem-phys.net/6/4633/2006/ acp-6-4633-2006-supplement.zip).

\section{Appendix A}

\section{Description of models 1 and 2}

The mobility-diameter growth factor $g$ is calculated from the measurements as follows:

$g(\mathrm{RH})=\frac{d_{m}(\mathrm{RH})}{d_{m, \text { dry }}}$,

where $d_{m \text {,dry }}$ is the mobility diameter of the dry particle (viz. $\mathrm{RH}<5 \%$ ) and $d_{m}(\mathrm{RH})$ is the mobility diameter at increased relative humidity. Literature accounts suggest that submicron dry ammonium sulfate particles are slightly nonspherical, having a shape factor $\chi$ that ranges from 1.07 to 1.03 as particle size decreases from 500 to $160 \mathrm{~nm}$ (Zelenyuk et al., 2006). The restructuring shown in Fig. 6 for increasing RH also demonstrates that the shape factor differs slightly from 1.00 (e.g., 1.02; see further discussion in main text). The following development of the models nevertheless assumes that the dry ammonium sulfate particles have a unity shape factor, in which case $d_{m \text {, dry }}=d_{v e, \text { dry }}$, where $d_{v e}$ denotes the volume-equivalent diameter. After deliquescence, the aqueous particles are also spherical, implying that $d_{m}(\mathrm{RH})=d_{v e}(\mathrm{RH})$. For these conditions, Eq. (A1) then simplifies to $g(\mathrm{RH})=d_{v e}(\mathrm{RH}) / d_{v e}$, dry. (For development of the case $\chi \neq 1.00$, see Biskos et al., 2006b).

We consider two models of the mobility-diameter growth factor: the first omits the Kelvin effect and the second includes it (Biskos et al., 2006a). Omission of the Kelvin effect implies that $a_{w}=\mathrm{RH} / 100$ for model 1 , where $a_{w}$ is the water activity in the aqueous particles. Model 1 is described by the following equation:

$g(\mathrm{RH})=\frac{d_{v e}(\mathrm{RH})}{d_{v e, \text { dry }}}=\left(\frac{100 \rho_{s}}{w_{t}\left(a_{w}\right) \rho\left(w_{t}\left(a_{w}\right)\right)}\right)^{1 / 3}$,

where $\rho_{s}$ is the density of the dry particle, $\rho\left(w_{t}\left(a_{w}\right)\right)$ is the density of the aqueous solution droplet, and $w_{t}\left(a_{w}\right)$ is the weight percent of solute in the aqueous particle. Equations for these quantities are given in Table 1.

Model 2 expands on model 1 by including the Kelvin effect, which relates RH to $a_{w}$ as follows:

$\mathrm{RH}=100 a_{w} \exp \left(\frac{4 M_{w} \sigma_{a q}\left(w_{t}\left(a_{w}\right)\right)}{R T \rho_{w} d_{v e}(\mathrm{RH})}\right)$,

where $\rho_{w}$ is the density of pure water, $\sigma_{a q}\left(w_{t}\left(a_{w}\right)\right)$ is the surface tension of the aqueous droplet (Table 1), $M_{w}$ is the molar mass of water, $R$ is the universal gas constant, and $T$ is the temperature. Model 2 predicts $g(\mathrm{RH})$ by solving for $d_{v e}(\mathrm{RH})$ and $a_{w}(\mathrm{RH})$ that simultaneously satisfy Eqs. (A2) and (A3).

Plots of $g(\mathrm{RH})$ based on models 1 and 2 are shown in Fig. 5 as the solid and dot-dashed lines, respectively.

Acknowledgements. This material is based upon work supported by the National Science Foundation under Grant No. 0304213. Any opinions, findings, and conclusions or recommendations expressed in this material are those of the authors and do not necessarily reflect the views of the National Science Foundation. We thank M. Wise and R. Bahadur for their useful discussion and suggestions.

Edited by: J. Abbatt

\section{References}

Allan, J. D., Alfarra, M. R., Bower, K. N., Coe, H., Jayne, J. T., Worsnop, D. R., Aalto, P. P., Kulmala, M., Hyotylainen, T., Cavalli, F., and Laaksonen, A.: Size and composition measurements of background aerosol and new particle growth in a Finnish forest during QUEST 2 using an Aerodyne Aerosol Mass Spectrometer, Atmos. Chem. Phys., 6, 315-327, 2006, http://www.atmos-chem-phys.net/6/315/2006/. 
Ball, S. M., Hanson, D. R., Eisele, F. L., and McMurry, P. H.: Laboratory studies of particle nucleation: Initial results for $\mathrm{H}_{2} \mathrm{SO}_{4}$, $\mathrm{H}_{2} \mathrm{O}$, and $\mathrm{NH}_{3}$ vapors, J. Geophys. Res., 104, 23 709-23 718, 1999.

Biskos, G., Malinowski, A., Russell, L. M., Buseck, P. R., and Martin, S. T.: Nanosize effect on the deliquescence and the efflorescence of sodium chloride particles, Aerosol Sci. Technol., 40, 97-106, 2006a.

Biskos, G., Russell, L. M., Buseck, P. R., and Martin, S. T.: Nanosize effect on the hygroscopic growth factor of aerosol particles, Geophys. Res. Lett., 33, L07801, doi:10.1029/2005GL025199, 2006b.

Buzorius, G., McNaughton, C. S., Clarke, A. D., Covert, D. S., Blomquist, B., Nielsen, K., and Brechtel, F. J.: Secondary aerosol formation in continental outflow conditions during ACE-Asia, J. Geophys. Res., 109, D24203, doi:10.1029/2004JD004749, 2004.

Chen, D. R., Pui, D. Y. H., Hummes, D., Fissan, H., Quant, F. R., and Sem, G. J.: Design and evaluation of a nanometer aerosol differential mobility analyzer (Nano-DMA), J. Aerosol Sci., 29, 497-509, 1998.

Chen, J. P.: Theory of deliquescence and modified Köhler curves, J. Atmos. Sci., 51, 3505-3516, 1994.

Cohen, M. D., Flagan, R. C., and Seinfeld, J. H.: Studies of concentrated electrolyte solutions using the electrodynamic balance. 1 . Water activities for single-electrolyte solutions, J. Phys. Chem., 91, 4563-4574, 1987.

Cubison, M. J., Coe, H., and Gysel, M.: A modified hygroscopic tandem DMA and a data retrieval method based on optimal estimation, J. Aerosol Sci., 36, 846-865, 2005.

Cziczo, D. J., Nowak, J. B., Hu, J. H., and Abbatt, J. D. P.: Infrared spectroscopy of model tropospheric aerosols as a function of relative humidity: Observation of deliquescence and crystallization, J. Geophys. Res., 102, 18 843-18 850, 1997.

Djikaev, Y. S., Bowles, R., Reiss, H., Hämeri, K., Laaksonen, A., and Väkevä, M.: Theory of size dependent deliquescence of nanoparticles: Relation to heterogeneous nucleation and comparison with experiments, J. Phys. Chem. B, 105, 7708-7722, 2001.

Gao, Y. G., Chen, S. B., and Yu, L. E.: Efflorescence relative humidity for ammonium sulfate particles, J. Phys. Chem., 110, 76027608, 2006.

Hämeri, K., Laaksonen, A., Väkevä, M., and Suni, T.: Hygroscopic growth of ultrafine sodium chloride particles, J. Geophys. Res., 106, 20 749-20 757, 2001.

Hämeri, K., Väkevä, M., Hanson, H.-C., and Laaksonen, A.: Hygroscopic growth of ultrafine ammonium sulphate aerosol measured using an ultrafine tandem differential mobility analyzer, J. Geophys. Res., 105, 22 231-22 242, 2000.

Kinney, P. D., Pui, D. Y. H., Mulholland, G. W., and Bryner, N. P.: Use of the Electrostatic Classification Method to Size $0.1 \mu \mathrm{m}$ SRM Particles - A Feasibility Study, J. Res. Natl. Inst. Stan., 96, 147-176, 1991.

Kulmala, M., Vehkamäki, H., Petäjdä, T., Dal Maso, M., Lauri, A., Kerminen, V. M., Birmili, W., and McMurry, P. H.: Formation and growth rates of ultrafine atmospheric particles: a review of observations, J. Aerosol Sci., 35, 143-176, 2004.

Martin, S. T.: Phase transitions of aqueous atmospheric particles, Chem. Rev., 100, 3403-3453, 2000.
McMurry, P. H.: A review of atmospheric aerosol measurements, Atmos. Environ., 34, 1959-1999, 2000.

Mikhailov, E., Vlasenko, S., Niessner, R., and Pöschl, U.: Interaction of aerosol particles composed of protein and salts with water vapor: hygroscopic growth and microstructural rearrangement, Atmos. Chem. Phys., 4, 323-350, 2004, http://www.atmos-chem-phys.net/4/323/2004/.

Mirabel, P., Reiss, H., and Bowles, R. K.: A theory for the deliquescence of small particles, J. Chem. Phys., 113, 8200-8205, 2000.

Napari, I., Noppel, M., Vehkamaki, H., and Kulmala, M.: An improved model for ternary nucleation of sulfuric acid-ammoniawater, J. Chem. Phys., 116, 4221-4227, 2002.

O’Dowd, C. D., Aalto, P., Hämeri, K., Kulmala, M., and Hoffmann, T.: Aerosol formation - Atmospheric particles from organic vapours, Nature, 416, 497-498, 2002.

Onasch, T. B., Siefert, R. L., Brooks, S. D., Prenni, A. J., Murray, B., Wilson, M. A., and Tolbert, M. A.: Infrared spectroscopic study of the deliquescence and efflorescence of ammonium sulfate aerosol as a function of temperature, J. Geophys. Res., 104, $21317-21326,1999$.

Perry, R. H. and Green, D. W.: Perry’s Chemical Engineers' Handbook, McGraw Hill, New York, 1997.

Pruppacher, H. R. and Klett, J. D.: Microphysics of Clouds and Precipitation, Kluwer Academic Publishers, Boston, 1997.

Rader, D. J. and McMurry, P. H.: Application of the tandem differential mobility analyzer to studies of droplet growth or evaporation, J. Aerosol Sci., 17, 771-787, 1986.

Romakkaniemi, S., Hämeri, K., Väkevä, M., and Laaksonen, A.: Adsorption of water on 8-15 nm NaCl and $\left(\mathrm{NH}_{4}\right)_{2} \mathrm{SO}_{4}$ aerosols measured using an ultrafine tandem differential mobility analyzer, J. Phys. Chem. A, 105, 8183-8188, 2001.

Russell, L. M. and Ming, Y.: Deliquescence of small particles, J. Chem. Phys., 116, 311-321, 2002.

Sakurai, H., Fink, M. A., McMurry, P. H., Mauldin, L., Moore, K. F., Smith, J. N., and Eisele, F. L.: Hygroscopicity and volatility of 4-10 $\mathrm{nm}$ particles during summertime atmospheric nucleation events in urban Atlanta, J. Geophys. Res., 110, D22S04, doi:10.1029/2005JD005918, 2005.

Smith, J. N., Moore, K. F., Eisele, F. L., Voisin, D., Ghimire, A. K., Sakurai, H., and McMurry, P. H.: Chemical composition of atmospheric nanoparticles during nucleation events in Atlanta, J. Geophys. Res., 110, D22S03, doi:10.1029/2005JD005912, 2005.

Stolzenburg, M. R. and McMurry, P. H.: TDMAFIT User's Manual, Particle Technology Laboratory, Department of Mechanical Engineering, University of Minnesota, Minneapolis, MN, USA, 1988.

Tang, I. N. and Munkelwitz, H. R.: Aerosol phase-transformation and growth in the atmosphere, J. Appl. Meteorol., 33, 791-796, 1994.

Tang, I. N., Tridico, A. C., and Fung, K. H.: Thermodynamic and optical properties of sea salt aerosols, J. Geophys. Res., 102, 23 269-23 275, 1997.

Topping, D. O., McFiggans, G. B., and Coe, H.: A curved multicomponent aerosol hygroscopicity model framework: Part 1 - Inorganic compounds, Atmos. Chem. Phys., 5, 1205-1222, 2005 , http://www.atmos-chem-phys.net/5/1205/2005/. 
Weis, D. D. and Ewing, G. E.: Infrared spectroscopic signatures of $\left(\mathrm{NH}_{4}\right)_{2} \mathrm{SO}_{4}$ aerosols, J. Geophys. Res., 101, 18 709-18 720, 1996.

Wise, M. E., Biskos, G., Martin, S. T., Russell, L. M., and Buseck, P. R.: Phase transitions of single salt particles studied using a transmission electron microscope with an environmental cell, Aerosol Sci. Technol., 39, 849-856, 2005.

Zelenyuk, A., Cai, Y., and Imre, D.: From agglomerates of spheres to irregularly shaped particles: Determination of dynamic shape factors from measurements of mobility and vacuum aerodynamic diameters, Aerosol Sci. Technol., 40, 197-217, 2006.
Zhang, Q., Stanier, C. O., Canagaratna, M. R., Jayner, J. T., Wornsnop, D. R., Pandis, S. N., and Jimenez, J. L.: Insights into the chemistry of new particle formation and growth events in Pittsburgh based on aerosol mass spectrometry, Env. Sci. Technol., 38, 4797-4809, 2004. 